\title{
FIM DO SUJEITO? CRÍTICA AOS EXTREMOS PÓS-MODERNOS E PÓS- ESTRUTURAIS DA TEORIA CURRICULAR
}

\section{THE END OF SUBJECT? CRITICISM TO EXTREME POST-MODERN AND POST- STRUCTURAL CURRICULUM THEORY}

\author{
¿FIN DEL SUJETO? CRÍTICA A LOS EXTREMOS POSMODERNOS Y \\ POSEXTRUTURALES DE LA TEORÍA CURRICULAR
}

Márden De Pádua Ribeiro*

\begin{abstract}
Resumo: O presente artigo aborda uma contraposição às críticas desenvolvidas por Tomaz Tadeu da Silva à teoria curricular crítica no texto "Monstros, ciborgues e clones: os fantasmas da Pedagogia Crítica" que integra a obra "Pedagogia dos Monstros: os prazeres e os perigos da confusão de fronteiras", organizada pelo mesmo autor. Apesar de suas importantes contribuições para o campo de pesquisa curricular, questiona-se, aqui, a posição adotada pelo autor citado ao estancar a teoria curricular crítica, condenando-a à estagnação e ao determinismo. O artigo defende possibilidades de diálogo entre as concepções críticas, pós-modernas e pós-estruturais e também traz uma discussão conceitual acerca das distinções entre pós-modernismo e pós-estruturalismo. Por fim, enfatiza uma concepção curricular crítica que acolhe algumas contribuições pós-modernas sem, no entanto, desconsiderar algumas de suas concepções.
\end{abstract}

Palavras-chave: Currículo. Teorias críticas. Teorias pós-modernas.

Abstract: This article discusses a contrast to the criticism developed by Tomaz Tadeu da Silva to the critical curricular theory in the text "Monsters, cyborgs and clones: the ghosts of Critical Pedagogy", which includes the book "Pedagogy of Monsters: the pleasures and dangers of the borders of confusion", organized by the same author. Despite his important contributions to the field of curriculum research, it is questioned here the position adopted by the author in stopping the critical curricular theory, condemning it to stagnation and determinism. This paper defends possibilities for dialogue between the critical conceptions, postmodern and post-structural and also brings a conceptual discussion about the distinctions between postmodernism and post-structuralism. Finally, it emphasizes a critical curriculum conception that welcomes some postmodern contributions, without, however, disregarding some of their conceptions.

Keywords: Curriculum. Critical theories. Post-modern theories.

Resumen: Este artículo discute un contraste a la crítica desarrollada por Tomaz Tadeu da Silva, la teoría curricular crítica en el texto “ Monstros, ciborgues e clones: os fantasmas da Pedagogia Crítica”, que incluye la obra "Pedagogia dos Monstros: os prazeres e os perigos da confusão de fronteiras”, organizada por el mismo autor. A pesar de sus importantes contribuciones al campo de la pesquisa curricular, se pregunta, aquí, la posición adoptada por el autor citado, para detener la teoría curricular

\footnotetext{
* Mestre em Educação pela Pontifícia Universidade Católica de Minas Gerais - PUCMG. Professor do Curso de Pedagogia da Faculdade de Ciências Sociais Aplicadas de Belo Horizonte - FACISABH. Assessor Pedagógico da Faculdade de Minas. E-mail: mardendepadua@yahoo.com.br
} 
crítica, condenándola al estancamiento y el determinismo. El artículo defiende posibilidades de diálogo entre las concepciones críticas posmodernas y posestructurales y también trae una discusión conceptual acerca de las distinciones entre el posmodernismo y posestructuralismo. Por fin, enfatiza una concepción curricular crítica que da la bienvenida a algunas aportaciones posmodernas, sin embargo, sin desconsiderar algunas de sus concepciones.

Palabras claves: Currículo. Teorías críticas. Teorías posmodernas.

\section{Introdução}

O presente trabalho é resultado dos estudos desenvolvidos por um Grupo de Pesquisa de uma instituição de ensino superior brasileira. No Grupo, além de diversas outras temáticas, têm-se aprofundado também alguns estudos acerca das influências da chamada pós-modernidade para o campo do currículo e sua relação com teorizações críticas curriculares.

O texto tem por objetivo apresentar uma contraposição às críticas feitas por Tomaz Tadeu da Silva em seu texto "Monstros, ciborgues e clones: os fantasmas da Pedagogia Crítica” e discutir as aproximações e os distanciamentos entre as teorias críticas e pós-modernas de currículo. O referido texto faz parte da obra "Pedagogia dos Monstros: os prazeres e os perigos da confusão de fronteiras”, organizada e traduzida pelo mesmo autor.

A obra, datada do ano de 2000, é composta, além da introdução desenvolvida por Tomaz Tadeu, por mais quatro ensaios de autores estrangeiros (James Donald, Jeffrey Jerome Cohen, Ian Hunter, José Gil), todos já publicados fora do Brasil, entre 1992 e 1996, e coletados por Tomaz Tadeu para a publicação no Brasil, sem alterações. A metodologia utilizada partiu de uma reflexão teórica com base em pesquisa bibliográfica (MARCONI; LAKATOS, 2002).

A influência do pós-modernismo no campo da teoria curricular não é fenômeno tão recente assim. Já há quase 20 anos, Moreira
(1997, p. 9) constata tal presença: “tem-se acentuado, nos últimos anos, a influência do pensamento pós-moderno no discurso curricular contemporâneo, tanto no Brasil como em outros países.” Macedo (2013, p. 438) faz a mesma constatação, afirmando que, a partir da década de 1990, "a hegemonia quase absoluta do pensamento marxista entra em declínio nos estudos curriculares, com a forte incorporação, pelo campo, de perspectivas pós-estruturais.”

A autora salienta ainda que se trata justamente de Tomaz Tadeu Silva a responsabilidade central na divulgação das matrizes pós-estruturalistas no Brasil, sobretudo, através de seus trabalhos em traduções e em seus próprios grupos de pesquisa. Esse novo perfil de publicações em torno da teoria curricular influenciou a superação da vertente marxista por uma concepção marcadamente pós-estrutural, embora a autora saliente que algumas categorias da teorização crítica ainda permeiem o campo curricular.

Produções recentes têm se notabilizado por uma abordagem pós-estrutural do currículo, cuja ênfase na linguagem e na textualidade parecem, hoje, ter alcançado uma hegemonia que outrora a teorização crítica marxista alcançou. Notadamente, destacamos os trabalhos de Pereira (2012), que concebe o currículo como uma "teia de significados", e Macedo (2006), que entende o currículo como um "espaço-tempo" cujos sentidos de conhecimento e de cultura são constantemente produzidos, mas também negociados e disputados. Macedo $(2006,2013)$ recusa-se ainda a 
pensar o currículo como produtor de identidade e tece críticas à já clássica formulação de Tomaz Tadeu ${ }^{1}$ (2009) que concebe o currículo como um produtor de identidades sociais.

Em recente artigo, Paraíso (2015) discorre sobre o currículo, permeando-o entre sonhos, delírios e encantos, até defendê-lo como um "vetor de matéria-força”, constituído de “matéria-forma”, sem perder de vista sua dimensão enquanto "espaço de possibilidades”:

Um currículo pode estar feito da mesma matéria dos sonhos, nos quais tudo é possibilidade? Um currículo pode estar feito da mesma matéria da literatura, da filosofia vitalícia, da pintura, da poesia, de toda arte que sonha, delira, cria, encanta e faz sonhar? Um currículo pode estar feito da mesma matéria dos filmes que estão constantemente inventando outros possíveis? Em síntese: um currículo pode estar feito da mesma matéria de uma vida - que é como um mar aberto ou "uma onda do mar" onde "tudo move, tudo muda o tempo todo”? [...] É claro que, para isso, um currículo precisa de outros pensamentos, raciocínios; ele necessita de uma outra lógica. A busca de uma lógica para um currículo que esteja atenta às sensações; uma lógica para pensá-lo como um vetor de matéria-força para o aprender. (PARAÍSO, 2015, p. 49-50).

Conforme abordado anteriormente, produções recentes continuam a produzir sentidos pós-estruturais ao currículo, o que reforça ainda mais nossa suposição de que, atualmente, trata-se de concepção hegemônica no campo. Ou, em palavras mais pós-estruturais, constituem-se como discursos predominantes.

\footnotetext{
${ }^{1}$ Usaremos aqui Tomaz Tadeu ao invés de Silva, para diferenciar de Maria Aparecida Silva, que também será muito utilizada no trabalho, no intuito de tornar menos confusa a leitura.
}

\section{Conceituando: pós-modernismo}

A influência do pós-modernismo no campo da teoria curricular não é fenômeno tão recente assim. Já há quase 20 anos, Moreira (1997, p. 9) constata tal presença: “[...] tem-se acentuado, nos últimos anos, a influência do pensamento pós-moderno no discurso curricular contemporâneo, tanto no Brasil como em outros países.” Macedo (2013, p. 438) faz a mesma constatação, afirmando que a partir da década de 1990 “[...] a hegemonia quase absoluta do pensamento marxista entra em declínio nos estudos curriculares, com a forte incorporação, pelo campo, de perspectivas pós-estruturais.”

Pós-estruturalismo e pós-modernismo, embora não sejam sinônimos, são geralmente confundidos como tal. Peters (2000, p. 12) chega a afirmar que alguns críticos argumentam que o "[...] conceito de pós-estruturalismo deve ser subordinado ao de pós-modernismo.” No entanto, de acordo com Peters (2000), é preciso distinguir os dois termos, a começar pela relação que ambos possuem com seus respectivos objetos teóricos: estruturalismo e modernismo.

O modernismo, segundo o autor, possui um duplo viés: o primeiro refere-se aos movimentos artísticos de meados do final do século XIX, e o segundo possui uma matriz histórica e filosófica cuja ideia de moderno desemboca na concepção de "modernidade”: uma época posterior à era medieval. Filosoficamente, o modernismo, nessa acepção histórica e filosófica, inicia-se através do inglês Francis Bacon e do francês René Descartes. Acerca dessa acepção filosófica da modernidade, o autor conclui:

[...] o modernismo pode ser visto, na filosofia, como um movimento baseado na crença no avanço do conhecimento, desenvolvido a partir da experiência e por meio 
do método científico. Seu auge se dá, provavelmente, com a filosofia de Immanuel Kant e com a ideia de que o avanço do conhecimento exige que as crenças tradicionais sejam submetidas à operação da crítica. (PETERS, 2000, p. 13).

O pós-modernismo, nesse sentido histórico e filosófico, constitui-se como um período posterior, que representa uma mudança radical no sistema de valores e práticas oriundas da modernidade. No entanto, o autor salienta que os significados tanto do termo "modernismo" quanto do "pós-modernismo” não são estáticos, ou seja, têm mudado historicamente, a partir de produções teóricas que os ressignificam e reconstroem. "Nesse sentido, podemos dizer que não existe um fechamento em torno de uma definição única.” (PETERS, 2000, p. 16).

Sendo assim, seus significados serão sempre questionáveis e, de certo modo, polissêmicos. Para Giroux (1993, p. 43), no que diz respeito ao pós-modernismo, “[...] não há nenhum significado consensual para o termo”. Por isso mesmo, há uma tendência a imbricar o pós-modernismo e o pós-estruturalismo, sobretudo a partir de suas concepções em comum, ainda que existam diferenças entre ambos. É natural que alguns autores percebam o pós-modernismo como um termo mais abrangente e que compreende dentro de si uma vertente pós-estrutural. No entanto, vale ressaltar, posteriormente, as diferenças entre ambos. Peters sugere algumas premissas básicas da acepção pós-moderna que, independente da heterogeneidade de seu significado, se mantêm consolidadas: “[...] não existe qualquer denominador comum a natureza ou a verdade ou Deus ou o futuro - que garanta que o mundo seja Uno ou a possibilidade de um pensamento natural ou objetivo.” (PETERS, 2000, p. 16).

Essa desconfiança em relação a conceitos totalizantes, comuns na modernidade, constitui-se como condição básica para que a pós-modernidade apresente-se como ruptura. Essa forma "moderna” de ver o mundo é a grande questão a ser combatida. Lyotard sintetiza bem esta concepção totalizante da modernidade:

Quando este metadiscurso recorre explicitamente a algum grande relato, como a dialética do espírito, a hermenêutica do sentido, a emancipação do sujeito racional ou trabalhador, o desenvolvimento da riqueza, decide-se chamar "moderna” a ciência que a isto se refere para se legitimar. (LYOTARD, 1984, p. 34).

Em outras palavras, a pós-modernidade, portanto, nos dizeres de Lyotard (1984), seria a desconfiança, a recusa na crença das metanarrativas e no sujeito emancipado através de uma progressiva consolidação da razão. Segundo Peters (2000), estas grandes narrativas são nada mais nada menos do que histórias que determinadas culturas contam sobre suas próprias crenças e práticas, no intuito de respaldá-las. Ao consolidar tais desconfianças, o pós-modernismo se apresenta como uma concepção filosófica que apresenta uma alternativa ao paradigma moderno. Moreira (1997) sintetiza características comuns acerca do ideário pós-moderno:

a) o abandono das grandes narrativas; b) a descrença em uma consciência unitária, homogênea, centrada; c) a rejeição da ideia de utopia; d) a preocupação com a linguagem e com a subjetividade; e) a visão de que todo discurso está saturado de poder; f) a celebração da diferença. (MOREIRA, 1997, p.10).

Vale ressaltar que o pós-modernismo não é homogêneo, como também não o é o pós-estruturalismo. Contudo, a síntese acima de Moreira (1997), vai ao encontro do que Lyotard (1984) ressalta a respeito do 
pós-modernismo, ao também analisá-lo sob o prisma da ruptura com as grandes narrativas, da crítica à consciência unitária, autocentrada e universalista de sujeito, típico da Modernidade, e a descrença à ideia de utopia. Tais noções são corroboradas nas palavras de Eagleton:

[...] pós-moderno quer dizer, aproximadamente, o movimento de pensamento contemporâneo que rejeita totalidades, valores universais, grandes narrativas históricas, sólidos fundamentos para a existência humana e a possibilidade de conhecimento objetivo. O pós-modernismo é cético a respeito de verdade, unidade e progresso, apõe-se ao que vê como elitismo na cultura, tende ao relativismo cultural e celebra o pluralismo, a descontinuidade e a heterogeneidade. (EAGLETON, 2005, p. 27).

Para Lyotard (1984), o pós-modernismo está intrinsecamente relacionado às questões de conhecimento e tecnologia que produzem novas formas de organização social, que acabam por afrouxar os laços e valores oriundos da modernidade. Para o autor, tal vertente contribui para que indivíduos passem a traçar seu próprio caminho, sem o auxílio de referências totalizantes da modernidade. Nesse sentido, para Lyotard (1984), o mundo pós-moderno é instável, no qual o conhecimento muda constantemente e cujo significado é sempre um discurso momentâneo sobre algo.

Nas palavras de Lopes (2013), o pós-modernismo pode ser caracterizado pelo fim do otimismo em relação ao humano, em um contexto de barbárie no século XX (duas guerras mundiais, fascismos, bomba atômica, genocídios). Com isso, ganha corpo um movimento que passa a desconfiar do projeto iluminista: os mesmos princípios que eram vistos como garantidores da emancipação humana passam a ser encarados como um sistema de opressão universal em nome da libertação humana. Como sintetiza a autora:

Como características gerais do pós-modernismo, podemos apresentar a incredulidade perante as metanarrativas de legitimação da ciência e da ação humana, com as suas pretensões atemporais, a-históricas, totalizantes e universalizantes: dialética do espírito (Hegel), emancipação do sujeito racional ou do trabalhador. Igualmente são colocados em crise conceitos como razão e, portanto, verdade e totalidade, bem como os conceitos de sujeito, progresso, espaço e tempo linear. (LOPES, 2013, p. 10).

Para Lopes (2013), o único consenso entre pós-modernos é justamente a impossibilidade de consenso, e que não há uma narrativa total e abrangente capaz de explicar o mundo. Não existe a possibilidade de um lugar objetivo de onde se possa falar e nomear o mundo fora da história, da linguagem, das construções discursivas, das identidades e experiências. Parece não mais haver princípios que possam agir como critérios de valor universais transcendentais para coisa alguma. "Lidamos com uma nuvem dispersa de elementos narrativos heterogêneos, sempre no campo dos dissensos.” (LOPES, 2013, p. 11).

O pós-modernismo privilegia a heterogeneidade e a diferença, valoriza a indeterminação, a fragmentação, o efêmero, o descontínuo, o inacabado, sem pretender definir em nenhum momento o que há de eterno, universal, total e imutável nessa dispersão. Nesse sentido, para a autora, o pós-modernismo é uma reação ao modernismo, um afastamento dele, não uma sucessão linear à modernidade.

Interessante notar que, já no início da década de 1990, McLaren (1993, p. 23) alertara para a polissemia que gira em torno do pós-modernismo, que, segundo o autor, “é um termo fugidio e seus referentes estão saturados de significados que se sobrepõem.” 
Ainda salienta que o pós-modernismo revela novas tendências em relação às teorias acerca do sujeito. É importante destacar um “quadro de momento”, em que o autor analisa como era visto o pós-modernismo naquele determinado momento, associando-o a uma "moda acadêmica”. Curioso notar que, se de fato era moda, não se consolidou como passageira, tendo em vista que hoje, passados mais de vinte anos, continua a ser uma questão central à teoria curricular, com ares cada vez maiores de complexidade:

As ambiguidades de significado do pós-modernismo e a crescente variedade de conotações em torno do conceito têm proliferado muito nos últimos anos. Essa confusão, associada ao caráter frouxo da terminologia usada para descrever mudanças pós-modernistas na teoria social, tem sido responsável por grande parte da conotação negativa que o termo tem adquirido ao longo dos últimos anos, ao tornar-se um dos tópicos da moda na academia. [...] O termo serve, contraditoriamente, ao mesmo tempo, para alimentar as pretensões dos acadêmicos da alta burguesia norte-americana e para servir como referencial para a crítica ideológica e para a política emancipatória. O crescente interesse entre os educadores com respeito á discussão que ganha agora uma grande publicidade - sobre a questão de saber se vivemos ou não numa conjuntura pós-moderna e sobre as implicações dessa discussão toda para a avaliação do legado da tradição iluminista moderna está extraordinariamente vivo. (MCLAREN, 1993, p. 24).

Fica evidente que, já àquela época, a problemática da modernidade com o paradigma iluminista universal se constituíam como o epicentro da ruptura que o pós-modernismo representaria. Polissemias à parte, o pós-modernismo refere-se concretamente ao modernismo, como buscamos ressaltar e, dito isto, torna-se importante buscar definir o objeto teórico sob o qual se assenta o pós-estruturalismo, no sentido de clarear suas diferenças em relação ao pós-modernismo, mas também identificar suas premissas em comum.

\section{Conceituando: pós-estruturalismo}

Do mesmo modo que é preciso explanar a respeito do modernismo/modernidade para estabelecer o vínculo direto com o pós-modernismo, faz-se necessário detalhar o objeto teórico no qual se referencia a vertente pós-estrutural: isto é, o estruturalismo. Segundo Peters (2000), o estruturalismo tem sua origem na linguística estrutural, desenvolvida por Saussure, na França. Sem querer detalhar tal vertente (este não é o objetivo), é importante ressaltar que nessa concepção, o sistema linguístico, sobretudo a partir de Saussure, é constituído por diferentes níveis de estrutura e possui uma certa lógica científica, que dava ao estudo da linguagem uma ideia de sistema de signos que possuía base metodológica. Peters (2000) salienta ainda que a partir de Roman Jakobson, parceiro de Saussure, o termo "estruturalismo" se consolidou, se desenvolveu e se expandiu.

Uma abordagem estruturalista, nesses moldes, segundo Peters (2000, p. 22), corresponde à ênfase em investigações científicas dos fenômenos, no intuito de "[...] revelar leis internas de um sistema determinado.” Nesse sentido, qualquer fenômeno deve ser analisado a partir de um todo estrutural. O autor detalhará ainda que, a partir da década de 1940, a influência da antropologia, por meio de Lévi-Strauss, exercerá papel fundamental no desenvolvimento do estruturalismo, assim como, em décadas posteriores, pensadores como Lacan e Althusser também possuem, em seus respectivos arcabouços teóricos, premissas estruturalistas. Posteriormente, o 
próprio Jean Piaget passa a analisar e discutir o estruturalismo, décadas mais tarde, em outro contexto. Retirar-se-á trecho da obra de Piaget, a partir de Peters (2000), de modo a sintetizar a definição de estruturalismo construída pelo psicólogo suíço:

Em uma primeira aproximação, podemos dizer que uma estrutura é um sistema de transformações. Na medida em que é um sistema e não uma simples coleção de elementos e de suas propriedades, essas transformações envolvem leis: a estrutura é preservada ou enriquecida pelo próprio jogo de suas leis de transformação, que nunca levam a resultados externos ao sistema nem empregam elementos que lhe sejam externos. Em suma, o conceito de estrutura é composto de três ideias-chave: a ideia de totalidade, a ideia de transformação e a ideia de auto-regulação. (PIAGET apud PETERS, 2000, p. 25).

Peters (2000) observa, amparado em Foucault, que o estruturalismo, heterogêneo e complexo, possuía interesse central para a questão do sujeito. $\mathrm{O}$ autor salienta que as distintas correntes pós-estruturais convergiam na medida em que recusavam amplamente o primado do sujeito, em outras palavras, a concepção dominante, desde René Descartes, de um sujeito cartesiano, puramente racional e que servira de base para diversas abordagens filosóficas posteriores.

Pós-estruturalismo, para Peters (2000), tal qual pós-modernismo, não pode ser encarado de forma homogênea e estática, apresentando também distinções sob suas definições. $\mathrm{O}$ autor analisa que tal vertente, de um modo geral, pode ser caracterizada por um modo de pensamento, um estilo de filosofar e uma forma de escrita: “podemos dizer que o termo é um rótulo utilizado na comunidade acadêmica de língua inglesa para descrever uma resposta distintivamente filosófica ao estruturalismo.” (PETERS, 2000, p. 28).
Nesse sentido, Peters (2000, p. 29) defende que a vertente pós-estruturalista deve ser associada a um "movimento de pensamento”, e não a um método, ou teoria. Esta ideia de movimento diz melhor da complexidade que o envolve e da multiplicidade de correntes de pensamento que o cercam. O autor detecta que, na França, tal acepção se desenvolveu de forma mais consolidada em um primeiro momento, sobretudo a partir da segunda guerra mundial, a partir das contribuições de Sartre e da fenomenologia de Heidegger: “[...] provavelmente o mais importante é que o pós-estruturalismo inaugura e registra a recepção francesa de Nietzsche. [...] É também decisiva para a emergência do pós-estruturalismo a interpretação que Martin Heidegger fez de Nietzsche.” (PETERS, 2000, p. 29). A partir da década de 1970, novas leituras de Nietzsche, estabelecidas por Deleuze, Derrida e até mesmo Foucault consolidaram e complexificaram ainda mais a acepção pós-estrutural. A centralidade de Nietzsche nesse processo é assim explicada pelo autor:

Considerava-se que, enquanto Marx havia privilegiado a questão do poder e Freud havia dado prioridade à ideia do desejo, Nietzsche era um filósofo que não havia privilegiado qualquer um desses conceitos em prejuízo do outro. Sua filosofia oferecia uma saída que combinava poder e desejo. (PETERS, 2000, p. 30).

Os pensadores pós-estruturalistas, como já afirmado, não são coesos, nem articulados homogeneamente em termos de ideias e propostas, com várias posições expressas no desenvolvimento de formas peculiares de análise dirigidas à crítica de instituições específicas (família, Estado, prisão, clínica, escola, fábrica, forças armadas, universidade e filosofia) e para a teorização de uma ampla gama de diferentes meios (leitura, escrita, ensino, televisão, artes visuais, artes plásticas, 
cinema, comunicação eletrônica). Segundo Aparecida Silva (2006, p. 5), é neste contexto que se insere a crítica do pós-estruturalismo ao currículo "[...] na perspectiva humanista, na tecnicista e, ainda, às propostas emancipatórias de currículo seja na vertente marxista, seja na vertente libertária.”

[...] Estes estudiosos, ao rejeitarem as grandes narrativas, ao questionarem um conhecimento universal e a distinção entre alta cultura e a cultura cotidiana abrem espaço para currículos vinculados às diferenças culturais. Os estudos de currículo dentro desta perspectiva têm como objetivo o processo de construção e desenvolvimento de identidades mediante práticas sociais, privilegiando a análise de discurso. (APARECIDA SILVA, 2006, p. 5).

Esta defesa de um descentramento do sujeito, típico do pós-estruturalismo, ganha ainda mais força com as contribuições de Derrida, sempre pelas releituras da obra de Nietzsche. Para Peters (2000, p. 32), o descentramento da estrutura e do sujeito soberano pode ser percebido na obra de Derrida, a partir da "crítica dos conceitos de ser e de verdade”. Com a obra de Nietzsche, sob influência da crítica que este filósofo realiza ao conceito de verdade, vários teóricos pós-estruturalistas adotaram novas saídas teóricas. Nessa passagem, Peters (2000, p. 32) explora a contribuição de cada um dos pensadores, de modo sucinto:

Foucault desenvolveu a genealogia nietzscheana como uma forma de história crítica que resiste á busca por origens e essências, concentrado-se, em vez disso, nos conceitos de proveniência e emergência. Ao analisar, por meio do uso de narrativas, a pragmática da linguagem, Lyotard demonstra a mesma aversão que tinha Nietzsche pelas tendências universalizantes da filosofia moderna. Derrida, seguindo Nietzsche, Heidegger e Saussure, questiona os pressupostos que governam 0 pensamento binário, demonstrando como as oposições binárias sustentam, sempre, uma hierarquia ou economia de valor que opera pela subordinação de um dos termos da oposição binária ao outro, utilizando a desconstrução para denunciar e reverter essas hierarquias. Deleuze fixa-se na diferença como elemento característico que permite substituir Hegel por Nietzsche. (PETERS, 2000, p. 32).

Segundo Aparecida Silva (2006, p. 4), em meio à heterogeneidade do pós-estruturalismo, há uma visão consensual: “Todos esses pensadores enfatizam o significado como construção ativa, dependente da pragmática do contexto, em oposição à suposta universalidade das chamadas asserções de verdade.” Nesse sentido, a verdade é produto de gêneros discursivos, e o sujeito, ao invés de racional, livre e autônomo, constitui-se como inconcluso, inacabado, descentrado. Em outras palavras, a partir de Nietzsche, esses estudiosos questionam o sujeito cartesiano-kantiano humanista. Ou, nas palavras de Peters (2000, p. 33), recusam a ideia de um sujeito “[...] autônomo, livre e transparentemente autoconsciente, que é tradicionalmente visto como fonte de todo o conhecimento e da ação moral e política.” Em contrapartida, para o pós-estruturalismo, esse sujeito, além de descentrado, é dependente de um sistema linguístico (aqui o pós-estruturalismo se mantém atrelado ao estruturalismo). Este sujeito é discursivamente constituído e “[...] posicionado na intersecção entre as forças libidinais e as práticas socioculturais.”

Nesse ponto, estruturalismo e pós-estruturalismo possuem afinidades. Ambos tecem críticas a essa acepção de sujeito racional e autônomo, tradicionalmente vinculados à modernidade. Recusam, ainda, a noção de conhecimento científico universal, capaz de 
fornecer verdades sobre o mundo. Para Peters (2000, p. 37), tanto o estruturalismo quanto o pós-estruturalismo “[...] tem uma dívida direta com Freud”. Afinal, a partir de Freud e de sua análise do inconsciente, houve certamente um abalo à visão filosófica dominante, fundamentada na racionalidade. Para Peters (2000), grande parte das ênfases pós-estruturais encaminhadas em direção à questão do desejo, do corpo, da sexualidade são influências diretas de Freud. A partir de Freud, esse sujeito, de fato, não seria mais o mesmo, não possui mais tanto poder assim sobre si e não é tão pleno e centrado como acredita ser. Afinal, como nos diz Freud (1977, p. 294), “[...] o eu não é senhor dentro de sua própria morada.”

Para Lopes (2013), pós-estruturalismo e pós-modernismo se cruzam, se mesclam mas também podem se confrontar. A autora identifica uma tradição teórica em comum, que remete de Nietzsche, Heidegger e Derrida e identifica algumas premissas que podem ser cruzadas em ambas as vertentes: “[...] são marcadamente anti-essencialistas, anti-objetivistas, críticos dos determinismos e valorizam a linguagem como central na mediação da compreensão do social, substituindo as estruturas pelo discurso e ampliando as discussões filosóficas da cultura.” (LOPES, 2013, p. 17). A autora salienta que ambas as concepções impactam o campo do currículo na medida em que problematizam as chamadas teorias críticas de cunho sociológico e favorecem a recuperação de enfoques fenomenológicos e autobiográficos. "Mas, sobretudo, no meu entender, impactam nas formas como compreendemos noções centrais do campo, com consequências significativas para as conexões entre currículo e política.” (LOPES, 2013, p. 18).

Moreira (1997) ressalta que tanto o pós-modernismo bem como o pós-estruturalismo, quando relacionados à Educação, irão rejeitar a ideia de futuro como algo norteador para a construção de uma escola e de um currículo que podem operar como resistências, em busca de uma sociedade mais justa. Outra acepção pós-moderna e pós-estrutural que atinge a uma teorização crítica diz respeito à questão do conhecimento: “[...] no pensamento pós-moderno todos os conhecimentos são meros discursos, textos ou signos, não se coloca a questão da validade, o que permite vinculá-lo a uma posição relativista mais forte que a encontrada na abordagem crítica do currículo.” (MOREIRA, 1997, p. 17).

Embora a crítica ao sujeito constitua-se como ponto comum importante entre estruturalismo e pós-estruturalismo, há no estruturalismo uma pretensão de identificar estruturas universais que seriam comuns a todas as culturas e à psique humana de um modo geral. $\mathrm{O}$ ataque ao universalismo constitui-se em importante ponto de divergência entre pós-estruturalismo e estruturalismo. Em oposição aos paradigmas universalistas, o pós-estruturalismo tende a enfatizar as noções de diferença, de determinações locais, de desconstrução e também busca valorizar a subjetividade, sobretudo a percepção do inconsciente como algo que interfere em nosso comportamento.

Em outras palavras, o sujeito, categoria já colocada em crise no próprio estruturalismo, é questionado ainda mais centralmente pelo pós-estruturalismo. No estruturalismo, como discutem Peters (2000) e Lopes (2013), há um enfoque na estrutura como forma de questionar o primado do sujeito. "Ao penso, logo sou cartesiano é contraposto o penso onde não sou, sou onde não penso lacaniano.” (LOPES, 2012, p. 12). Com o pós-estruturalismo, busca-se questionar tanto a estrutura quanto o sujeito, com base no que Lopes (2013, p. 13) denominou como "anti-humanismo heideggeriano”. 
Entretanto, Lopes (2013) pondera que tal assertiva pós-estrutural não se trata de uma eliminação do sujeito, colocando-se contrária à expressão “morte do sujeito” mencionada por alguns autores pós-estruturais. Para a autora, a desconstrução do sujeito (sua “morte”) é o seu descentramento, “[...] o questionamento do seu caráter de origem ou fundamento, tal como também se opera ao questionar a estrutura.” (LOPES, 2013, p. 14). O sujeito existe, nesse sentido, como efeito do significante, como resultado de escolhas discursivas capazes de fechar, sempre provisoriamente, a significação. A radicalidade deste discurso pode levar à “eliminação do sujeito”, que não é corroborado por Lopes (2013) mas parece ser a perspectiva defendida por Silva (2000), em texto destinado a tecer duras críticas à chamada pedagogia crítica.

Um ilustrativo exemplo de como a vertente pós-estrutural, que defende uma "eliminação” do sujeito, constrói suas premissas está na obra "Pedagogia dos Monstros: os prazeres e os perigos da confusão de fronteiras”, organizada e traduzida por Tomaz Tadeu Silva, sendo que, a introdução dessa obra, de sua autoria, intitulada "Monstros, ciborgues e clones: os fantasmas da Pedagogia Crítica”, é totalmente direcionada a atacar a teoria crítica curricular, associando-a a algo mais amplo (pedagogia crítica) e relacionando-a a esses paradigmas mencionados anteriormente. Nesse texto, Tomaz Tadeu Silva traz uma concepção extrema de pós-estruturalismo, eliminando o sujeito e tecendo críticas, a nosso ver, injustas em direção à teoria crítica curricular.

\section{Situando a concepção de Tomaz Tadeu: descrevendo os "fantasmas" da pedagogia crítica}

Tomaz Tadeu (2000) no início de seu texto, destinado a criticar aquela que por ele é denominada de “teoria crítica”, já anuncia, em tom apoteótico, a seguinte sentença:

Senhoras e senhores, lamentamos informar que o sujeito da educação já não é mais o mesmo. Este parece ser o anúncio mais importante da teoria cultural e social recente. O sujeito racional, crítico, consciente, emancipado ou libertado da teoria educacional crítica entrou em crise profunda. (TOMAZ TADEU, 2000, p. 13).

Percebe-se claramente que, desde já, o autor afirma certa “crise” da teoria crítica, relacionando-a ao fato de ela se dar concomitantemente a uma crise do "sujeito racional, crítico”. Se ele não é mais o mesmo, portanto, ao que parece, ele não existe mais. É esta a sentença que o autor dá a entender nesse primeiro momento.

Para Tomaz Tadeu (2000, p. 13), as bases da chamada pedagogia crítica são abaladas desde o momento em que há um questionamento em relação à ideia de sujeito "centrado, unificado e homogêneo da tradição humanista”. Mais adiante, o autor relaciona esta concepção de sujeito a algo cartesiano, oriundo do início da Idade Moderna, através da clássica afirmativa do filósofo René Descartes: “penso, logo existo”. Essa frase ficaria profundamente marcada por uma concepção racional, centrada e unificada de sujeito, que, com o advento da pós-modernidade, sobretudo, após a influência da Psicanálise, sofreu forte abalo, como ressalta o autor.

A partir de Freud, esse sujeito, de fato, não seria mais o mesmo, não possui mais tanto poder assim sobre si e não é tão pleno e centrado como acredita ser. Afinal, como nos diz Freud (1977, p. 294), “[...] o eu não é senhor dentro de sua própria morada.” No entanto, Tomaz Tadeu (2000) parece levar tal assertiva às últimas consequências, deslocando totalmente o sujeito do consciente para o inconsciente. Indo além, o autor evidencia 
ainda, através das contribuições de Foucault, que o sujeito é uma espécie de efeito de discursos sobre si mesmo:

É com a chamada "teoria pós-estruturalista” e com as perspectivas chamadas de "pósmodernas", entretanto, que a "teoria do sujeito" vai se tornar claramente insustentável. Com Foucault, o "sujeito" não passa de um efeito das práticas lingüísticas e discursivas que o constroem como tal. Se, para a Psicanálise, o sujeito não é quem ele pensa que é, para Foucault, o sujeito não é nada mais do que aquilo que dele se diz. $\mathrm{O}$ "sujeito”, mais do que originário e soberano, é derivado e dependente. O "sujeito” que conhecemos como base e fundamento da ação é, na verdade, um produto da história. (TOMAZ TADEU, 2000, p. 15).

Mais adiante, após tecer hermética análise das contribuições de Derrida para esta questão, Tomaz Tadeu sentencia, basicamente, o fim do sujeito:

Com Derrida, a subjetividade dissolve-se na textualidade. O “sujeito”, se é que ele existe, não passa de simples inscrição: ele é pura exterioridade. Não há lugar, aqui, para qualquer "teoria do sujeito" ou "filosofia da consciência”. (TOMAZ TADEU, 2000, p. 16).

Não satisfeito, prossegue determinado a acabar de vez com o "sujeito”, criado na Modernidade e que, para o autor, a teoria crítica curricular o aceita amplamente. Após abarcar Freud, Foucault e Derrida, o tiro de misericórdia é desenvolvido através de dois teóricos, também caros ao pós-estruturalismo: Deleuze e Guatarri. Para Tomaz Tadeu (2000), a partir destes dois, a crítica ao sujeito se radicaliza, e finalmente pode-se exterminá-lo, afinal, o mundo é constituído por "máquinas”. Tal concepção é assim explicada:

É com Deleuze e Guattari, entretanto, que o questionamento da "teoria do sujeito" se radicaliza. Em oposição a Foucault e Derrida, que questionam o "sujeito" da "filosofia da consciência” sem se arriscarem a propor nada em troca, Deleuze e Guattari desenvolvem toda uma pragmática da subjetividade na qual desaparecem quaisquer referências a "sujeitos" como entidades ou substâncias concebidos como centros ou origens da ação humana. Para começar, o mundo é concebido como sendo constituído de “máquinas” que se definem não por qualquer caráter essencial mas simplesmente porque produzem: o que interessa são só seus efeitos. Como tal, não há qualquer distinção entre “máquinas” biológicas, humanas, mecânicas, eletrônicas, naturais, sociais, institucionais... As máquinas se caracterizam pelos fluxos que circulam entre elas: certas máquinas emitem fluxos que são “interrompidos” por outras máquinas, as quais, por sua vez, produzem outros fluxos, que são “interrompidos”, etc. (TOMAZ TADEU, 2000, p. 16-17).

As máquinas de Tomaz Tadeu (2000) correspondem a algo de propositivo dentro do pós-estruturalismo. O autor esclarece que tanto Foucault como Derrida atacam a "teoria do sujeito”, mas sem sugerir algo novo. Eis as máquinas, como uma proposta radical de Deleuze e Guatarri. Tal acepção nos faz questionar: o que resta de nós, pessoas, em um mundo de máquinas sem distinções? Há espaço para transformações sociais? Há espaço para a intervenção na realidade?

A respeito de tais questões, o autor irá criticar duas premissas, segundo ele, centrais na teoria crítica: a ideia de que existe uma sociedade, no singular, e a visão de que a teoria crítica irá formar a consciência crítica dos sujeitos para modificar essa sociedade, no singular.

A persistente consigna que tem estado no centro de todas as vertentesdessa pedagogia pode ser sintetizada na fórmula "formar 
a consciência crítica”. Pode-se variar a fórmula, substituindo o verbo por "produzir", “educar”, “desenvolver”; o substantivo por “cidadão”, "pessoa”, “homem”, “sujeito”, "indivíduo" e o adjetivo por "consciente", "reflexivo", "participante”, "informado”, "integral", entre tantas outras possibilidades. O pressuposto é, entretanto, sempre o mesmo: que existe algo como um núcleo essencial de subjetividade que pode ser pedagogicamente manipulado para fazer surgir o seu avatar crítico na figura do sujeito que vê a si próprio e à sociedade de forma inquestionavelmente transparente, adquirindo, no processo, a capacidade de contribuir para transformá-la. (TOMAZ TADEU, 2000, p. 13).

A realização do sujeito ideal da pedagogia crítica depende, igualmente, da aceitação de uma epistemologia realista pela qual se supõe a existência de um referente último e “objetivo” — “a” sociedade —, acessível apenas a uma ciência crítica da sociedade e, espera-se, ao sujeito plenamente realizado da pedagogia crítica. No quadro da chamada "virada lingüística”, torna-se altamente questionável continuar sustentando que exista uma coisa chamada "a” sociedade. (TOMAZ TADEU, 2000, p. 16).

O que é, portanto, o teórico crítico para Tomaz Tadeu? Um sujeito (ou máquina?) que acredita que a sociedade é única e unificada e que irá transportar para outras pessoas a tal consciência crítica, "iluminando" os outros com a criticidade "ideal” para transformar essa sociedade, sempre no singular. Como veremos posteriormente, é impensável imaginar teóricos críticos renomados como Michael Apple, Henri Giroux, Peter McLaren, ou até mesmo Paulo Freire, corroborarem essas premissas. Mas para Tomaz Tadeu (2000) todos aderem a essa "fórmula" e partem desses mesmos pressupostos, tal qual explicitado em citação anterior.

O autor, com alguma ironia, enquadra toda a teoria crítica, reafirmando a ideia de fórmula que se encontra em crise, desacreditada. Ancorada na defesa de uma consciência crítica, Tomaz Tadeu (2000) afirma que tal visão é fruto de uma pretensão totalizante, insustentável nos dias atuais.

Esta rica e querida fórmula já não nos parece tão tranquila. Poucos acreditam, hoje, numa visão transparente da sociedade, a qual, para começar, supõe uma concepção da sociedade como única e unificada. Além disso, a soberana posição de uma "consciência crítica” baseia-se no pressuposto da existência de uma teoria total da sociedade que se torna insustentável num contexto no qual as metanarrativas de qualquer gênero são olhadas com profunda desconfiança. (TOMAZ TADEU, 2000, p. 13).

Percebe-se que há uma coerência na lógica do autor: se o sujeito é descentrado, inconsciente, fruto de efeitos discursivos e, portanto, quase que incapaz de intervenção em uma realidade, que por si só também é algo mais abstrato do que de fato concreto, é natural não haver nenhuma possibilidade de contribuir para a formação crítica de outra pessoa. O teórico crítico, para Tomaz Tadeu (2000), seria uma espécie de “super-herói crítico”, aquele que de modo imponente surge para transferir aos pobres mortais a dita "consciência crítica” que irá transformar a sociedade, no singular. Ao que parece, há nessa ideia um elemento de imposição e autoritarismo, à medida que esse sujeito seria o dono de uma verdade redentora e que, portanto, deveria ser transmitida aos outros.

A questão, então, não é defender a existência de um “super-herói crítico” capaz de tais feitos incríveis. Pelo contrário, e nesse sentido, partilhamos dessa impossibilidade. O estranhamento se dá na medida em que Tomaz Tadeu (2000) desloca para a teoria crítica, ou pedagogia crítica, tais premissas (fórmulas), como se essa vertente defendesse 
a ideia cartesiana, de modo quase positivista, ou "bancário", nos termos de Freire (2013), um sujeito que, diante de sua potência racional, iluminasse com sua crítica tudo e todos, transformando a realidade, como se a realidade não fosse um jogo de conflitos, de disputas, de ressignificações e de distintas concepções de mundo.

Procuraremos demonstrar que o autor desconsiderou os avanços teóricos desenvolvidos por autores da teoria crítica curricular ao longo dos anos, os quais atualmente encontram-se muito longe (se é que já estiveram próximos) de tais premissas atribuídas à vertente crítica.

Ao detalhar a quem está se referindo, Tomaz Tadeu (2000) explicita não só quem é este teórico crítico, mas também sua origem e sua inclinação para enxergar a sociedade como algo linear, exato, estando ele "apto a consertá-la”. Está aqui embutida toda a ideia de “super-herói crítico" que o autor tenta atribuir a tal vertente:

O sujeito crítico da pedagogia crítica é a réplica perfeita do sociólogo crítico da educação que, de sua posição soberana - livre dos constrangimentos que produzem a turvada compreensão da sociedade que têm os indivíduos comuns -, vê a sociedade como se vê um mecanismo de relógio, tornando-se apto, assim, a consertá-la. (TOMAZ TADEU, 2000, p. 12-13).

Aceitar tais analogias e relações feitas por Tomaz Tadeu (2000) é não só considerar que os teóricos críticos citados de fato defendem estas “fórmulas”, mas também tornar quase impossível um diálogo, alguma integração entre teoria crítica curricular e as vertentes pós-modernas e pós-estruturais. Acatar suas percepções também é afirmar a impossibilidade, a impotência perante a realidade. É sobrevalorizar o discurso e desvalorizar a possibilidade de interferência nas múltiplas e complexas realidades. Amparar-se em tais premissas é condenar o sujeito e sua capacidade racional de intervenção, ainda que mínima. É matar o sujeito, sepultar qualquer utopia.

Vale resgatar, novamente, que Tomaz Tadeu (1993), no início da década 1990, tinha a mesma preocupação em relação aos “pós”: o de que a descrença total em um sujeito racional, unitário, poderia impossibilitar a crítica, a proposição e possíveis contribuições para a diminuição da opressão, sobretudo, no âmbito educacional. Pelo que se pôde notar, o autor não possui mais essa preocupação. $\mathrm{O}$ sujeito morreu, e da pedagogia crítica restaram “fantasmas”. Contudo, resgatamos aqui também os fantasmas do próprio autor que, décadas atrás, ousou defender um diálogo entre a vertente crítica e as vertentes pós-modernas e se preocupou com os excessos de discursos imobilizadores.

A questão que se coloca, portanto, é se existe possibilidade de um diálogo entre uma abordagem crítica e pós-moderna, no que tange ao currículo. Estaria a teoria crítica curricular ultrapassada pela concepção pós-moderna? Não teria mais nada a contribuir nesse sentido?

Em Tomaz Tadeu Silva temos duas respostas distintas a estas perguntas. No início da década de 1990, Tomaz Tadeu (1993) demonstrava, ao fazer um balanço a respeito do pós-modernismo, que o foco de suas narrativas locais, parciais, fragmentárias não deveria impedir uma percepção macro, não se poderia perder de vista a dimensão social e global. O autor se mostra ainda preocupado com certo excesso de teorizações a respeito do discurso e compreende que a celebração das diferenças, embora cruciais, corre o risco de obscurecer estruturas sociais concretas e seus impactos na vida das pessoas. Alerta também para o risco de uma descrença total no sujeito centrado moderno, que pode levar a uma 
impotência que impossibilita qualquer transformação possível na estrutura educacional.

No entanto, passados alguns anos, Tomaz Tadeu mudou de ideia, como se pôde perceber na obra citada no início desse texto. Iremos nos ater mais detalhadamente nesse texto-discurso, ressaltando as críticas que o autor faz à teorização crítica, abandonando qualquer tentativa, que outrora havia feito, de uma possível combinação entre pós-modernismo e teoria crítica.

Rebatemos, neste texto, as duras críticas de Tomaz Tadeu à teoria crítica, problematizando suas conclusões e ressaltando não só as contribuições que tal vertente crítica ainda tem a oferecer à teoria curricular, mas, sobretudo, enfatizando que o autor não compreendeu com exatidão o desenvolvimento da teoria crítica, julgando-a de modo equivocado e estagnado. $\mathrm{O}$ autor a identifica como uma teoria que parece não ter avançado, desde os teóricos da reprodução das décadas de 1960 e 1970, e que ainda defende os mesmos pressupostos, o que de fato, não procede.

Encarar a teoria crítica do modo pelo qual o autor a concebeu é desconsiderar a pedagogia crítica de McLaren (1997), a pedagogia da possibilidade de Giroux (1997), os estudos educacionais críticos neomarxistas de Apple (2006), as contribuições de Paulo Freire, (para citar somente alguns) que em nada se relacionam com o modelo de teoria crítica que Tomaz Tadeu (2000) resolveu criticar em seu texto.

Reafirma-se aqui um estranhamento, ao inferirmos que o autor estacionou numa certa concepção crítica ortodoxa, determinista, que entende o sujeito de modo totalmente cartesiano e que pretende "formar a consciência crítica” de alguém, como se fosse portadora de uma verdade absoluta, crítica e transformadora. Certamente não é essa a vertente crítica dos teóricos mencionados acima.
É curioso observar a entrevista dada ao periódico "Currículo sem Fronteiras", dois anos mais tarde, quando perguntado sobre como avaliava o desenvolvimento da produção teórica sobre o currículo. O autor respondeu da seguinte maneira:

Toamaz Tadeu: É possível que eu tenha me alienado da produção atual na área da teoria curricular e, como consequência, o que vou dizer a seguir talvez possa ser creditado apenas à minha falta de informação. [...] Nos últimos tempos, tenho-me afastado bastante desse tipo de atividade, digamos, "pública”, retirando-me para o interior de minhas próprias elucubrações e preocupações intelectuais. Não por qualquer veleidade de autossuficiência, mas simplesmente como resultado de um processo pessoal de mudança intelectual. É dessa perspectiva relativamente isolada (ou solitária?) que digo que o campo da teoria curricular passa por uma fase de relativa estagnação. É claro que falo aqui apenas daquelas tendências situadas à esquerda do espectro político no campo da teorização educacional e curricular. (GANDIN; PARASKEVA; HYPOLITO, 2002, p. 6).

Conforme observado, o próprio autor justifica que anda um pouco “afastado”, o que talvez tenha ocasionado em certa "alienação” em relação à produção na área do currículo. Talvez isso justifique o porquê, dois anos antes, Silva (2000), em seu texto, tenha vociferado contra uma pedagogia crítica que não é merecedora dos ataques que recebeu.

\section{Para uma outra concepção de teoria crítica do currículo}

Esta propalada crise da teoria crítica não é percepção exclusiva de Tomaz Tadeu (2000), pois Moreira (2010), Santos (2007) e Pacheco (2001) também se destinaram a analisar tal fenômeno. Analisaremos o trabalho 
de Moreira (2010) por se relacionar de modo mais direto com a temática proposta.

Na perspectiva de Moreira (2010), não se pode tratar a teoria crítica de forma homogênea, pois, ao estudar suas raízes, o autor constata que há, pelo menos, duas grandes linhas que congregam uma concepção crítica curricular: a primeira, hegemônica até a década de 1980, permaneceu fiel às abordagens estruturais e caracteriza-se pelo neomarxismo. A segunda, mais notada a partir dos anos de 1990, “[...] incorpora contribuições de estudos feministas, estudos de raça, estudos culturais e do pensamento pós-modernos e pós-estrutural.” (MOREIRA, 2010, p. 97).

Ainda nessa análise, o autor apresenta quatro fases pelas quais a teoria crítica perpassou e que, embora não lineares, e sim híbridas, mas que ainda assim possibilitaram verificar mudanças de foco a partir de uma sofisticação teórica. Não é objetivo aqui debruçar sob todas essas fases, e sim, na última, que vai ao encontro da temática proposta.

A quarta fase do desenvolvimento da vertente crítica se inicia nos anos de 1990 , a partir de questionamentos a respeito do neomarxismo predominante na década anterior. Tais críticas são oriundas justamente de vertentes pós-modernas e pós-estruturais, o que obriga a teoria crítica a revisitar-se, ponderar seus rumos e inevitavelmente absorver possíveis contribuições. O diálogo entre uma vertente crítica neomarxista, hegemônica na década de 1980, e as assertivas “pós” é controvertido e tenso, mas possível. Moreira (2010) chega a esboçar alguns teóricos que não conseguiam ver alguma possibilidade de integração entre estas duas correntes teóricas (ou entre esses dois discursos?), contudo ressalta que tal diálogo, (in)tenso, está na gênese da chamada "crise da teoria crítica".

Giroux (1993) já alertara sobre a possibilidade desse diálogo, ressaltando que a teoria crítica poderia aproveitar algumas percepções do pós-modernismo e pós-estruturalismo, porém sem perder de vista o compromisso com a justiça social, democracia, libertação e crítica às desigualdades. Todos esses valores “totalizantes”, em uma perspectiva excessivamente “pós”, acabam tornando-se fluidos, discursivos, quando não raramente ilusórios. $\mathrm{O}$ autor, portanto, defende que não se deve perder de vista a noção de totalidade, embora também não se deva desconsiderar a inserção da diferença dentro desse aspecto mais total:

Precisamos de teorias que expressem e articulem a diferença, mas precisamos também compreender como as relações nas quais as diferenças são constituídas operam como parte de um conjunto mais amplo de práticas sociais, políticas e culturais. (GIROUX, 1993, p. 53).

Questionar, problematizar e desconfiar dos paradigmas da modernidade, para Giroux (1993) não só é saudável, como é crucial, para os teóricos críticos, sobretudo, na concepção de conhecimento que emana do ideário moderno. Um conhecimento permeado pelos valores essencialmente europeus, cristão, branco e masculino, que não raramente cria dicotomias entre o que é considerado legítimo, associado à cultura de elite, daquilo que é ilegítimo, popular. "Contestar o modernismo significa redesenhar e remapear a própria natureza de nossa geografia social, política e cultural.” (GIROUX, 1993, p. 42).

É nesse sentido que Giroux (1993, p. 42) argumenta que algumas contestações feitas pelo pós-modernismo e pós-estruturalismo são importantes “[...] porque promete desterritorializar e redesenhar as fronteiras políticas, sociais e culturais do modernismo, insistindo ao mesmo tempo numa política da diferença racial, étnica e de gênero.” O autor faz uma ressalva importante: a crítica 
pós-moderna oferece saídas progressistas, mas também reacionárias, que, por isso mesmo, precisam ser examinadas com cautela, se caso deseja-se acolher criticamente algumas de suas contribuições.

A nosso ver, a grande contribuição de Giroux (1993) se dá no argumento de que a base de uma pedagogia crítica não necessita ser constituída a partir de uma escolha entre modernismo e pós-modernismo, ou estruturalismo e pós-estruturalismo. Giroux, amparado em Ernesto Laclau, defende que o pós-modernismo é uma modo diferente de modular temas e categorias da modernidade e não necessariamente significa uma brusca ruptura. Os dois discursos (moderno e pós-moderno), segundo o autor, fornecem elementos importantes aos educadores críticos:

[...] os ideais do projeto da modernidade que vinculam memória, agência e razão com a construção de uma esfera pública democrática precisam ser defendidos como parte de um discurso educacional crítico no interior das condições de existência do mundo pós-moderno e não em oposição a elas. (GIROUX, 1993, p. 43).

Em outras palavras, o que Giroux (1993) pretende é uma combinação entre aportes pós-modernos e concepções de uma teoria crítica (radical, nos termos do autor). Nesse sentido, o autor busca enfatizar o ataque pós-moderno às grandes narrativas, ou narrativas mestras. Ou, ainda, a crítica à noção de totalidade. Sendo assim, de certo modo, a crítica a essas grandes narrativas é importante, no sentido de tornar-nos atentos ao fato dessas narrativas correrem o risco de desaguar em asserções de verdades universais, que para Giroux (1993, p. 53) corresponderiam a "significados últimos".

Mas não se pode rejeitar todas as noções de totalidade, caso contrário corre-se o risco de nos prendermos a particularismos, que, para Giroux (1993, p. 53), não conseguem dar conta de explicar "como as muitas e diversas relações que constituem os sistemas sociais, políticos e globais mais amplos se inter-relacionam ou se determinam”. A combinação entre o discurso pós-moderno e o crítico necessita “[...] que a noção da totalidade seja adotada mais como um dispositivo heurístico do que como uma categoria ontológica.” (GIROUX, 1993, p. 53).

Necessitamos de teorias que articulem a diferença, o particular, mas também precisamos compreender como as relações nas quais as diferenças são constituídas operam, como parte de um conjunto mais amplo de práticas sociais, políticas e culturais. Giroux (1993) chega a sugerir, embora não desenvolva nem aprofunde o raciocínio, uma distinção importante, visando contrapor Lyotard. Tratase da diferenciação entre narrativas mestras e grandes narrativas, geralmente tidas como sinônimos na visão de Lyotard (1984). Mas para Giroux (1993) são coisas distintas: as narrativas mestras possuem um viés totalizante e autoritário, pois tentam subordinar todo ponto de vista específico a uma teoria totalizante. $\mathrm{O}$ autor exemplifica essas narrativas mestras através do feminismo, de versões ortodoxas do marxismo e da concepção do filósofo Max Weber. No entanto, as grandes narrativas seriam aquelas que "[...] tentam contar uma Grande Estória, tais como o surgimento do capital, do patriarcado ou do sujeito colonial.” (GIROUX, 1993, p. 54).

Como dito, o autor não vai além nesses direcionamentos; contudo, eles parecem interessantes por encararem de modo dialético a questão da totalidade. Dentro dessa distinção, advoga-se em favor do não abandono de algumas grandes narrativas, porém, com o devido cuidado de não recorrermos a narrativas mestras para explicá-las. Em outras palavras, ser contra uma ortodoxia teórica que subordina toda explicação em sua matriz conceitual 
não significa rejeitar grandes narrativas que abarcam um amplo conjunto de práticas da sociedade, da cultura.

Outra questão central que a teoria crítica curricular não pode abandonar é a importância da possibilidade de intervenção-atuação do sujeito, frente a sua realidade, seu mundo. Se por um lado, o sujeito racional, pleno, portador da crítica transformadora, é uma ilusão, por outro, a "morte” do sujeito, a impossibilidade de sua intervenção, seu total descentramento é um exagero, uma precipitação. Mas será por acaso?

A “morte” do sujeito, sua eliminação, sua total impossibilidade são combatidas também por Giroux (1993), já desde o início da década de 1990, desconfiado de que tal concepção, além de possivelmente despolitizada, ainda pode enfraquecer a possibilidade de grupos excluídos dos centros do poder de se afirmarem como agentes coletivos. Nas últimas décadas, com algumas vozes silenciadas tendo seus silêncios diminuídos, é estranho que se pretenda, em algumas correntes, "matar" o sujeito.

Quando justamente alguns marginais gritam por voz, quando estudos pós-coloniais querem fazer a sua própria teoria, quando o “outro" marginalizado pede por uma redefinição de seu posicionamento historicamente construído, surgem vertentes dispostas a "eliminar” o sujeito? Não seria ideologicamente suspeita essa morte prematura? Giroux (1993, p. 63) se posiciona: “[...] a morte do sujeito parece não apenas teoricamente prematura, mas também ideologicamente suspeita, uma vez que essa posição está sendo promovida principalmente por acadêmicos brancos, do sexo masculino, em universidades de elite." Para Eagleton (2005), algumas versões pós-modernas, destinadas a eliminar o sujeito, devem ser questionadas, pois oferecem uma noção despolitizada e se recusam a tratar a subjetividade em termos históricos e políticos.
McLaren (1997) e Giroux (1993) analisam que o pós-modernismo (e também o pós-estruturalismo) oferece aos educadores alguns importantes insights, que podem ser aproveitados como parte de uma teoria mais ampla, ancorada em uma pedagogia crítica. Permite-lhes uma variedade de discursos que possibilitam questionar a dependência de certezas e verdades absolutas. Oferece ainda a incorporação do contingencial, do específico, do local, dentro de uma concepção pedagógica libertadora.

Ao currículo, o pós-modernismo complexifica as relações entre cultura, poder e conhecimento. Ao invés de celebrar as narrativas “dos mestres”, o pós-modernismo questiona algumas certezas e verdades paradigmáticas, desnudando como essas assertivas, a bem da verdade, relacionam-se também com formas particulares de e visões específicas de mundo, travestidas de universalismo. Em uma passagem esclarecedora, Giroux (1993) elabora a síntese que busca, entre assertivas críticas e pós-modernas:

A ênfase pós-moderna na rejeição de formas de conhecimento e pedagogia que venham envolvidas no discurso legitimador do sagrado e do consagrado, sua rejeição da razão universal como um fundamento para as questões humanas, sua asserção de que todas as narrativas são parciais, e seu apelo para que se realize uma leitura crítica de todos os textos científicos culturais e sociais como construções históricas e políticas, fornecem as bases pedagógicas para radicalizar as possibilidades emancipatórias do ensino como parte de uma luta mais ampla pela vida pública democrática e pela cidadania crítica. (GIROUX, 1993, p. 65).

Moreira (2010) salienta que um teórico fundamental no neomarxismo dos anos de 1980, Michael Apple, também absorveu contribuições “pós”, sem abrir mão de sua 
fidelização à teoria crítica. Apple (2002), ao observar que a pedagogia crítica nos últimos tempos recebeu influência de acepções pósmodernas, ressalvou que embora tenha sido:

[...] muito útil na reconceituação do campo e suas políticas, isso também expôs o discurso à crítica de ter-se tornado muito teórico, abstrato, esotérico e sem ligação com os conflitos e lutas em que professores, estudantes e ativistas atuam. (APPLE. 2002, p. 137).

O autor embasa-se ainda Henry Giroux, ao comentar sobre a defesa de que a pedagogia crítica absorva as contribuições de discursos pós-modernos. Acerca de tal questão, Apple (2002) tece ainda o seguinte comentário:

Henry Giroux (1992) e outros defenderam tais discursos como necessários na pedagogia crítica, pois para se reconstruir o mundo deve-se primeiro aprender a falar uma nova linguagem e "novas idéias requerem novos termos”. Sem dúvida isso é correto. $\mathrm{Na}$ verdade, essa foi a posição que conscientemente adotei quando apresentei as teorias de Gramsci e Habermas pela primeira vez na educação, no início da década de 1970. (APPLE, 2002, p. 137)

Moreira (2010, p. 106) analisa que Michael Apple, embora reconheça que a categoria de classe social não dá mais conta de abarcar toda a complexidade da sociedade, por outro lado, “[...] recusa também a visão do mundo como um texto, capaz tanto de secundarizar a materialidade da realidade social, [...] como de estimular a equivocada crença de que mudanças no discurso provocam mudanças sociais.” Moreira (2010) sintetiza claramente o diálogo proposto por Michael Apple, na tentativa de integrar algo da teoria crítica, com elementos pós-estruturais e tece elogios a esta iniciativa:

Entretanto, em recente estudo, Apple associa elementos de análises neogramscianas com elementos de análises pós-estruturais, com o objetivo de demonstrar como as primeiras - com seu foco no Estado, na formação de blocos hegemônicos, em novas alianças sociais e na produção de consentimento - e as últimas - com seu foco no local - [...] podem ser empregadas criativamente no exame de políticas educacionais (APPLE, 1995). O esforço é alentador, por: (a) oxigenar interpretações mais ortodoxas, sem que ao mesmo tempo adesões apressadas se façam sentir, e (b) procurar combinar abstrações teóricas e o mundo real. (MOREIRA, 2010, p. 106).

Tanto Michael Apple, como também, sobremaneira, Henri Giroux e Peter McLaren, são influenciados por um teórico da pedagogia crítica, que, embora não seja especificamente do campo curricular, sua obra permeia em diversos âmbitos, questões centrais ao currículo. Trata-se de Paulo Freire ${ }^{2}$. Se há um teórico crítico que passa ao largo das conclusões tiradas por Tomaz Tadeu (2000) de que os teóricos da pedagogia crítica são adeptos da necessidade de formar a consciência crítica do sujeito, este é, sem dúvida, Paulo Freire, sobretudo, tomando por base a dimensão dialógica em sua obra.

A dialogicidade, conforme aponta Freire (1996), se fundamenta sob a percepção de que os sujeitos são atores de sua própria história e não vítimas de um determinismo fatalista que os condiciona na existência. No entanto, Freire (2013) defende que este sujeito está em constante processo de busca por ser mais, ou seja, compreende o ser humano

\footnotetext{
${ }^{2}$ Para maior aprofundamento sobre a contribuição de Paulo Freire à teoria curricular, ver os seguintes artigos: SCOCUGLIA, A. C. As reflexões curriculares de Paulo Freire. Revista Lusófona de Educação, Lisboa, v. 6, p. 81-92, 2005.

SAUL, A. M.; SILVA, A. F. G. O legado de Paulo Freire para as políticas de currículo e para a formação de educadores no Brasil. Revista brasileira Estudos pedagógicos, Brasília, v. 90, n. 224, p. 223-244, 2009.
} 
como uma espécie de vir-a-ser, jamais descolado de sua realidade e nunca ancorado em uma completude. Perceber a existência humana na perspectiva de ser mais é reconhecer o sujeito sempre em movimento, inconcluso, incompleto, historicamente inacabado.

Nesse sentido, o diálogo pressupõe a interação entre sujeitos que crescem a partir de suas diferenças, sobretudo, no respeito a elas, sempre em uma relação horizontal e jamais em uma transmissão de um para o outro, e sim de um com o outro. O diálogo pressupõe troca e uma busca por algo. Demanda abrir-se para o mundo, reconhecendo nossa posição de não saber sobre tudo, de inacabamento perante o mundo. Pretender "formar" alguém, transmitir a um outro determinada "consciência crítica”, para Freire (2013, p. 29), é justamente o antidiálogo, a domesticação do sujeito, “[...] é transformá-los em objeto que se devesse salvar de um incêndio.”

Conforme Moreira salienta (2010), renomados autores críticos (Apple, Giroux, McLaren, Freire), que na década de 1980 notabilizaram-se, não se isentaram de reexaminar-se, indo além de suas análises iniciais, estendendo-as, incluindo algumas contribuições de vertentes pós-modernas, sem, no entanto, abandonar seus compromissos com a teorização crítica, muito embora o grau de absorção dessa contribuição não tenha sido igual para todos. Mas, certamente, nenhum destes estudiosos defende as concepções abordadas por Tomaz Tadeu (2000) no que ele concebeu como teoria crítica.

É neste sentido que defendemos certa estagnação do autor a uma concepção ortodoxa de teoria crítica, que desconsidera os avanços teóricos desses autores. Parece-nos que a única ortodoxia aqui presente é na própria crítica homogeneizante de Tomaz Tadeu (2000) a uma concepção que, além de heterogênea, não parou no tempo, desenvolveu-se e absorveu novas análises, mas que não abre mão de defender algumas premissas "totais". Como afirma Moreira (2010, p. 107), apesar da propalada crise, a teoria curricular crítica incluiu novos aportes teóricos, "[...] o que sugere que o diálogo entre neos e pós, apesar das dificuldades que levanta, pode também ser proveitoso.”

\section{Considerações finais}

É importante ressaltar a centralidade de Tomaz Tadeu Silva na teoria curricular brasileira. É inegável sua contribuição para os estudos curriculares, tanto na divulgação de vertentes teóricas quanto na produção de obras que serviram de referência a todos que buscam conhecimentos da área curricular. De modo algum foi intenção deste trabalho questionar a relevância deste autor para as discussões do currículo, e sim problematizar suas afirmações especificamente na obra supracitada.

Evidente que o diálogo entre as vertentes críticas e as pós-modernas não é simples e, muitas vezes, acarreta em impasses teóricos e necessidade de se fazer escolha. Porém é inegável que ambas as correntes podem conversar, ressaltando-se as contribuições de cada uma.

Não se deve jamais homogeneizar tanto a teoria crítica, quanto o pós-modernismo, para que não se corra o risco de reduzir a pluralidade de abordagens inseridas dentro dessas duas grandes correntes. Tomaz Tadeu (2000), ao homogeneizar a teoria crítica curricular, acabou por desconsiderar não só suas contribuições para o campo do currículo, mas por creditar a ela fundamentos que muitos de seus principais teóricos de fato não defenderam.

A pós-modernidade, em sua multiplicidade, trouxe contribuições à vertente crítica, sobretudo no que tange à inserção de categorias pouco discutidas na teorização crítica, 
obrigando-a a repensar-se e a ressignificar-se. Contudo, seus excessos podem paralisar a potencialidade do sujeito de intervenção, ainda que mínima, em sua realidade. Podem representar a desesperança, o desencanto, a inércia, retirando do sujeito a utopia.

Desse modo, embasamos em Moreira (1997, p. 25) a análise derradeira que sintetiza precisamente a necessidade de não nos esquecermos da importância de uma teorização crítica curricular:

A despeito da desconfiança do pós-modernismo em relação ao pensamento utópico, vejo a utopia como necessariamente constitutiva do ato educativo. Defendo, por conseguinte, a presença de uma perspectiva utópica nas análises e propostas de currículo informadas pela tentativa de integrar os ideais da modernidade e as categorias pós-modernas. Se ainda se pretende a educação a favor de um mundo social mais justo, é preciso orientar o trabalho pedagógico com base em uma visão de futuro, em uma perspectiva utópica que desafie os limites do estabelecido, que afronte o real, que esboce um novo horizonte de possibilidades. (MOREIRA, 1997, p. 25).

\section{Referências}

APPLE, M. Ideologia e currículo. Porto Alegre: Artmed, 2006.

Podem as pedagogias críticas sustar as políticas de direita? Cadernos de Pesquisa, São Paulo, n. 116, p. 107-142, jul. 2002.

EAGLETON, T. Depois da teoria - um olhar sobre os estudos culturais e o pósmodernismo. Rio de Janeiro: Civilização Brasileira, 2005.

FREIRE, P. Pedagogia do oprimido. Rio de Janeiro: Paz e Terra, 2013.
- Pedagogia da autonomia: saberes necessários à prática educativa. São Paulo: Paz e Terra, 1996.

FREUD, S. Conferências introdutórias sobre Psicanálise (1916-1917) In:

Conferências introdutórias sobre
Psicanálise (Parte III). ESB Vol. XVI. Rio de Janeiro: Imago, 1977. p. 289-439.

GANDIN, L. A.; PARASKEVA, J. M.; HYPOLITO, Á. Mapeando a [complexa] produção teórica educacional - entrevista com Tomaz Tadeu da Silva. Currículo sem Fronteiras, [s.l.], v. 2, n. 1, p.5-14, jan./jun. 2002.

GIROUX, H. O pós-modernismo e o discurso da crítica educacional. In: SILVA, T. T. (Org.). Teoria educacional crítica em tempos pós-modernos. Porto Alegre: ArtesMédicas, 1993.

LOPES, A. R. C. Teorias pós-críticas, política e currículo. Educação, Sociedade \& Culturas, Porto, no 39, p.7-23, 2013.

LYOTARD, J. -F. A condição pós-moderna. Rio de Janeiro: José Olympio, 1984.

MACEDO, E. A noção de crise e a legitimação de discursos curriculares. Currículo sem Fronteiras, [s.l.], v. 13, n. 3, p. 436-450, 2013.

- Currículo como espaço-tempo de fronteira cultural. Revista Brasileira de Educação, Rio de Janeiro, v. 11, n. 32, p. 285-296, maio/ago. 2006.

MARCONI, M. A.; LAKATOS, E. M. Técnicas de pesquisa. São Paulo: Atlas, 2002.

MCLAREN, P. A vida nas escolas. Uma introdução à pedagogia crítica nos fundamentos da educação. Porto Alegre: Artes Médicas, 1997. 
Pós-modernismo, pós-colonialismo e pedagogia. In: SILVA, T. T. (Org.). Teoria educacional crítica em tempos pósmodernos. Porto Alegre: Artes Médicas, 1993. p. 9-40.

MOREIRA, A. F. B. A configuração atual dos estudos curriculares: a crise da teoria crítica. In: PARAISO, M. (Org.). Antonio Flavio Barbosa Moreira: pesquisador em currículo. Belo Horizonte: Autêntica, 2010. p. 95-117.

. (Org.). Currículo: questões atuais. Campinas: Papirus, 1997.

PACHECO, J. A. Teoria curricular crítica: os dilemas (e contradições) dos educadores críticos. Revista Portuguesa de Educação, Braga, v. 14, n. 1, p. 49-71, 2001.

PARAÍSO, M. A. Um currículo entre formas e forças. Educação, Porto Alegre, v. 38, n. 1, p. 49-58, jan./abr. 2015.

PEREIRA, T. V. Currículo como teia de significados. Revista Teias, Rio de Janeiro, v. 12, n.27, p. 161-176, jan./abr. 2012.

PETERS, M. Pós-estruturalismo e filosofia da diferença. Belo Horizonte: Autêntica, 2000.

SANTOS, L. L. Currículo em tempos difíceis. Educação em Revista, Belo Horizonte, v. 45, n.1, p. 291-306, jun. 2007.

SILVA, M. A. Currículo para além da pósmodernidade. In: REUNIÃO ANUAL DA ANPED, 29., 2006, Caxambu. Anais eletrônicos... Caxambu: ANPED, 2006. Disponível em: < http://29reuniao.anped. org.br/trabalhos/trabalho/GT12-2444--Int. pdf> . Acesso em: 15 abr. 2017.

SILVA, T. T. Documentos de identidade: uma introdução às teorias do currículo. Belo Horizonte: Autêntica, 2009.
- Monstros, ciborgues e clones: os fantasmas da pedagogia crítica. In:

Pedagogia dos monstros: os prazeres e os perigos da confusão de fronteiras. Belo Horizonte: Autêntica, 2000. . (Org.). Teoria educacional crítica em tempos pós-modernos. Porto Alegre: Artes Médicas, 1993. 